\title{
JUIN 1957
}

\section{REVUE}

\section{INTERNATIONA LE}

DE LA

\section{CROIX-ROUGE}

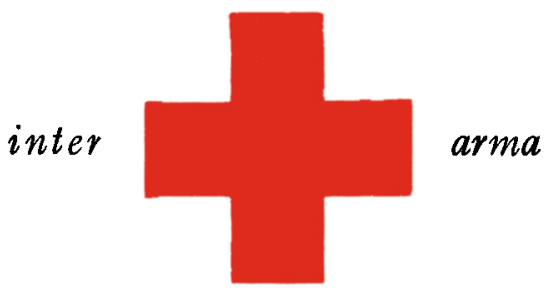

caritas

COMITE INTERNATIONAL DE LA CROIX-ROUGE GENE VE 


\section{COMITÉ INTERNATIONAL DE LA CROIX-ROUGE}

\section{à Genève}

MM. MAX HUBER, docteur en droit, ancien président de la Cour permanente de justice internationale, président d'honneur (1923) 1

LEOPOLD BOISSIER, docteur en droit, professeur honoraire de l'Université de Genève, ancien secrétaire général de l'Union interparlementaire, président (1946)

JACQUES CHENEVIERE, docteur is lettres h. c. (1919)

Mul LUCIE ODIER, ex-chef du Service des infirmières-visiteuses de la Section genevoise de la CroixRouge suisse (1930)

MM. CARL J. BURCKHARDT, docteur en philosophie, ancien ministre de Suisse en France (1933)

MARTIN BODMER, docteur en philosophie h. c., vice-president (1940)

ERNEST GLOOR, docteur en médecine (1945)

PAUL CARRY, docteur en droit, professeur à l'Université de Genève (1946)

EDMOND GRASSET, docteur en médecine, professeur à l'Université de Genève, directeur de l'Institut d'hygiène (1946)

PAUL RUEGGER, ancien ministre de Suisse en Italie et en Grande-Bretagne, membre de la Cour Permanente d'Arbitrage (1948)

HENRI GUISAN, général, ancien commandant en chef de l'armée suisse (1948)

ALFREDO VANNOTTI, docteur en médecine, professeur à l'Université de Lausanne (1949)

RODOLFO OLGIATI, ancien directeur du Don suisse (1949)

M $^{110}$ MARGUERITE VAN BERCHEM, ancien chef de service de l'Agence entrale des prisonniers de guerre (1951)

MM. FREDERIC SIORDET, avocat, conseiller du Comité international de la Croix-Rouge de 1943 à 1951, vice-president (1951)

MARCEL JUNOD, docteur en médecine, délégué du Comité international de la Croix-Rouge de 1935 a 1946 (1952)

GUILLAUME BORDIER, ingénieur dipl. E.P.F., M.B.A. Harvard, banquier (1955)

\section{Direction :}

MM. ROGER GALLOPIN, docteur en droit, directeur exécutif

JEAN S. PICTET, docteur en droit, directeur des Affaires générales

EDOUARD de BONDELI, sous-directeur, Services fnanciers et administratifs

CLAUDE PILLOUD, sous-directeur, Service juridique 


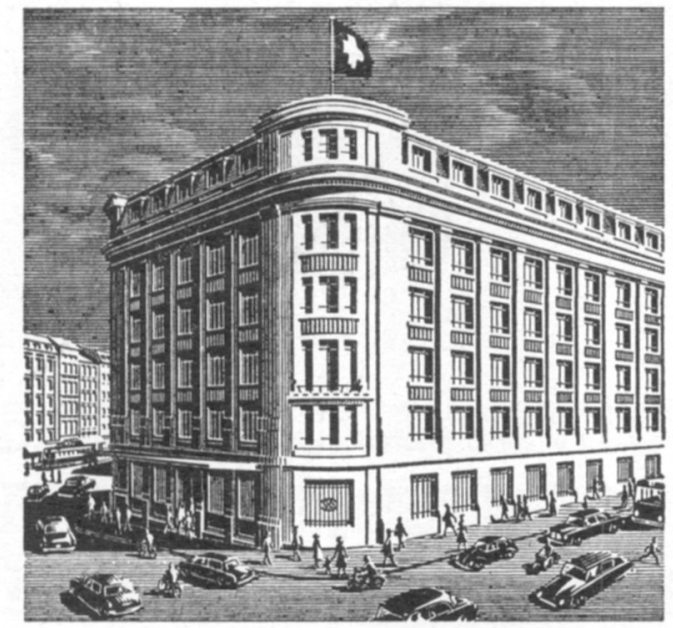

\section{SOCIETEE DE}

\section{BANQUE SUISSE} SCHWEIZERISCHER BANKVEREIN SOCIETA DI BANCA SVIZZERA SWISS BANK CORPORATION

\section{GENÈVE}

BALE BIENNE LA OHAUX-DE-FONDS LAUSANNE NEUOHATEL ST-GALL SOHAFFHOUSE ZURIOH LONDRES NEW-YORK

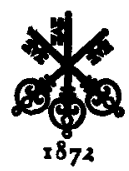

CAPITAL ET RESERVES FRS 275 MILLIONS 


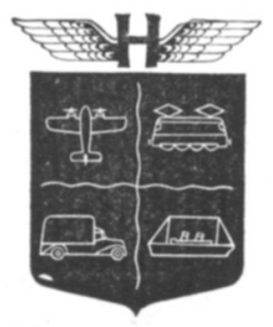

\title{
Compagnie d'Assurances Génépales l'HELLÉtIA Allgemeine Versicherungs-Gesellschaft HELUETIA General Insurance Company HELUETIa, Limiled
}

\author{
ST-GALL / ST. GALLEI \\ (SUISSE / SCHWEIZ / SWITZERLAND)
}

Fondée en 1858 / Gegründet 1858 / Estd. 1858

Frencs sulsees Schwolzerfranken Swles frencs

Capltal soclal / Aktienkapital / Share Capital: 10.000 .000 Moyens de garantle / Garantiemittel / Guarantee Funds : 72.484 .228

Primes brutes / Bruttoprămien / Gross Premlums 1956 : $\quad 51.151 .884$

Assurances transports et réassurances Transportversicherungen und Rückversicherungen Marine Insurance and Relnsurance 


\title{
REVUE INTERNATIONALE \\ DE LA CROIX-ROUGE
}

\author{
TRENTE-NEUVIEMME ANNEE - No 462 \\ JUIN 1957 \\ $*$
}

\section{SOMMAIRE}

R. Boppe : Un des fondateurs de la Croix-Rouge : Louis Appia (IV) . $\begin{array}{r}\text { Pages } \\ 299\end{array}$

\section{COMITÉ INTERNATIONAL DE LA CROIX-ROUGE}

Reconnaissance de la Croix-Rouge de la République du Vietnam

( $4 \mathrm{I} 5^{\text {me }}$ circulaire aux Comités centraux) . . . . . . .

Reconnaissance de la Croix-Rouge lao (4I6 $6^{\mathrm{me}}$ circulaire aux

Comités centraux) . . . . . . . . . . . . . 316

L'action du CICR en Hongrie . . . . . . . . . . . . . . 318

Nouvelle mission du CICR en Algérie . . . . . . . . . . 319

Mission du CICR dans la République fédérale allemande . . 320

Nouvelles brèves . . . . . . . . . . . . . . . . . 32 I

Conventions de Genève. . . . . . . . . . . . . . . . . . 330

\section{NOUVELLES DE SOCIÉTÉS NATIONALES}

Argentine . . . . . . . . . . . . . . . . . . . . . 332

Japon . . . . . . . . . . . . . . . . . . . . . . 335

\section{FAITS ET DOCUMENTS}

La dixième Assemblée mondiale de la Santé . . . . . . . . 337

Le vieillissement de la population . . . . . . . . . . . . . 343

\section{BIBLIOGRAPHIE}

\section{A TRAVERS LES REVUES}




\title{
SUPPLEMENTS DE LA REVUE
}

\author{
* \\ EN LANGUE ANGLAISE
}

Recognition of the Red Cross of the Republic of Vietnam (4 $5^{\text {th }}$ Circular to the Central Committees). - Recognition of the Laotian Red Cross (4I6th Circular to the Central Committees). - The action of the ICRC in Hungary. - Another ICRC mission to Algeria. - A mission of the ICRC to the German Federal Republic. - News Items. - A Japanese translation of the Commentary on the First Geneva Convention of I949.

\section{EN LANGUE ESPAGNOLE}

Reconocimiento de la Cruz Roja de la República del Vietnam (4I5.a Circular a los Comités Centrales). - Reconocimiento de la Cruz Roja Lao (4 6." Circular a los Comités Centrales). - Acción del CICR en Hungría. - Nueva misión del CICR a Argelia. - Missión del CICR en la República Federal de Alemania. - Noticias breves. Versión japonesa del Comentario del Primer Convenio de 1949. Noticias de Sociedades Nacionales: Argentina.

\section{EN I.ANGUE ALLEMANDE}

Anerkennung des Roten Kreuzes der Republik Vietnam (415. Rundschreiben an die Zentralkomitees). - Anerkennung des Roten Kreuzes von Laos (4I6. Rundschreiben an die Zentralkomitees). Die Aktion des IKRK in Ungarn. - Neue Mission des IKRK in Algerien. - Mission des IKRK in der Deutschen Bundesrepublik. Kurznachrichten. - Eine japanische Ausgabe des Kommentars zum ersten Genfer Abkommen von 1949.

\section{LA}

REVUE INTERNATIONALE DE LA CROIX-ROUGE est publiée chaque mois par le Comité international de la Croix-Rouge

7, avenue de la Paix, Genève (Suisse) - Compte de chèques postaux I. 1767

Abonnement un an : Fr. 20,-; le numéro Fr. 2,-

Pour les pays suivants : Algérie, Allemagne, Autriche, Belgique, Danemark, Finlande, France, Italie, Luxembourg, Maroc, Norvège, Pays-Bas, Portugal, Sarre, Suède, Tunisie, Vatican, on peut s'abonner aupres des bureaux de poste (Fr. s. 20,50).

Rédaction : JEAN-G, LOSSIER 